\title{
Avaliação microestrutural em matriz de aço ferramenta: com e sem falha em serviço
}

\author{
Lucas Pereira de Jesus \\ Instituto Federal Rio Grande do Sul (IFRS) - Campus Feliz \\ (lucaspj_@hotmail.com) \\ Cínthia Gabriely Zimmer \\ Instituto Federal Rio Grande do Sul (IFRS) - Campus Feliz \\ (cinthia.zimmer@feliz.ifrs.edu.br)
}

\begin{abstract}
Resumo: Matrizes são dispositivos metálicos que demandam alta resistência mecânica, pois exercerão em sua ação operações de corte, usinagem, conformação, injeção, entre outros. Geralmente são produzidas em aços ferramenta e requerem muita atenção sob o ponto de vista do controle dos procedimentos utilizados nos tratamentos térmicos. É sabido que as propriedades dos metais são função de sua microestrutura e, consequentemente, de sua história térmica. Nesse sentido as matrizes requerem uma combinação de propriedades que muitas vezes não podem ser restritas somente à dureza alcançada, mas principalmente à tenacidade. Quando esse aço é inadequadamente tratado pode ocorrer a formação de fases que fragilizam o material, propiciando falhas prematuras em serviço. Com o objetivo de otimizar fatores ligados ao tratamento térmico na linha de produção de uma empresa que atua na fabricação de matrizes, analisou-se dois componentes fabricados em aço ferramenta D6, ambos com dureza adequada para liberação comercial, contudo um apresentou falha prematura e o outro trabalhou anos sem nunca ter fraturado. Para tanto essas matrizes foram analisadas quanto a composição química em um espectrômetro de emissão ótica. A dureza foi determinada em um durômetro na escala Rockwell $\mathrm{C} \mathrm{e}$ pôr fim a análise microestrutural foi realizada em um microscópio óptico. Para isso amostras foram preparadas de acordo com procedimentos padrão de metalografia, onde se utilizou ataque químico Nital $10 \%$. A análise química apontou que os dois componentes apresentaram composição compatível ao aço ferramenta D6. Os valores de dureza testados foram de $58 \mathrm{HRC}$ para a matriz que rompeu em serviço e 59,5 HRC para matriz que não falhou. A avaliação microestrutural revelou que ambos componentes apresentaram microestrutura martensítica e presença de carbonetos, contudo a morfologia dos carbonetos era diferente. O dispositivo que não rompeu apresentava carbonetos esferoidais, mais homogêneos e finamente dispersos, enquanto a matriz que rompeu continha carbonetos alongados, tipo espinha de peixe, com maior tamanho e distribuição não uniforme. Um dos problemas atribuídos a esses carbonetos é que eles são anisotrópicos, tendo grande influência o sentido de atuação das tensões de trabalho. Quando dispostos no sentido longitudinal, e perpendicular às solicitações de compressão, podem atuar como iniciadores de trincas, reduzindo a resistência mecânica. A partir desses resultados serão estudadas rotas de tratamentos térmicos para formar carbonetos homogêneos, evitando a possibilidade de falha em serviço, o que gera transtornos e insatisfação de clientes.
\end{abstract}

Palavras-chave: Aço ferramenta; Tratamento térmico; Microestrutura.

\section{Microstructural evaluation of a tool steel die: with and without service failure}

Abstract: Dies are metallic devices that demand high mechanical resistance, because they will perform cutting, machining, forming, injection, among others. They are usually produced by tool steels and require close attention from the point of view of controlling the procedures used in heat treatments. It is well known that the properties of metals are a function of their microstructure and, consequently, of their thermal history. In this sense, the dies require a combination of properties that often cannot be restricted only to the hardness achieved, but mainly to the toughness. When this steel is improperly treated, it can occur phases that weaken the material, causing premature failures in service. In order to optimize factors related to heat treatment in the production line of a company that manufactures dies, two components made of D6 tool steel were analyzed, both with hardness suitable for commercial release, but one presented premature failure and the other one which worked years without ever fracturing. For this, these dies were analyzed as the chemical composition in an optical 
emission spectrometer. Hardness was determined on a Rockwell C scale durometer and finally the microstructural analysis was performed under an optical microscope. For this, samples were prepared according to standard metallography procedures, where Nital $10 \%$ chemical attack was used. The chemical analysis indicated that both components presented composition compatible to the tool steel D6. The hardness values tested were $58 \mathrm{HRC}$ for the die that failed in service and $59.5 \mathrm{HRC}$ for the die that did not failed. The microstructural evaluation revealed that both components presented martensitic microstructure and carbides presence, however the carbides morphology was different. The non-ruptured device had more homogeneous and finely dispersed spheroidal carbides, while the ruptured one contained elongated fishbone-type carbides of larger size and non-uniform distribution. One of the problems attributed to these carbides is that they are anisotropic, having a great influence on the working stresses. When arranged longitudinally, and perpendicular to compression demands, they can act as crack initiators, reducing mechanical strength. From these results, heat treatment routes will be studied to form homogeneous carbides, avoiding the possibility of failure in service, which generates inconvenience and customer dissatisfaction.

Keywords: Tool Steel; Heat Treatment; Microstructure.

\section{INTRODUÇÃO}

Os aços ferramenta para trabalho a frio da série "D" foram desenvolvidos comercialmente como um possível substituto dos aços rápidos durante a primeira guerra mundial. Entretanto, ao serem testados, apresentaram problemas pela redução de dureza quando utilizados em operações a quente. Porém sua alta resistência ao desgaste, devido aos carbonetos de cromo presente em sua microestrutura, aliado à sua indeformabilidade, resultou na aplicação deste aço para fabricação de matrizes. Devido sua composição química é muitas vezes conhecido como aço ferramenta de alto cromo e alto carbono, entretanto também apresenta molibdênio e vanádio. Suas aplicações são de matrizes e punções para cisalhamento e embutimento. No Brasil o aço D6 é o mais utilizado segundo Silva e Mei (2010).

A comercialização dos aços ferramentas geralmente ocorre no estado recozido, apresentando matriz ferrítica e carbonetos precipitados. Neste estado, apresenta baixa dureza para ser conformado e/ou usinado. Para seu uso final são temperados e revenidos para obter as propriedades mecânicas adequadas ao uso, como dureza, tenacidade e resistência ao desgaste. Finalmente sua microestrutura é composta de uma matriz de martensita revenida e carbonetos com diversos tamanhos, de acordo com Junior (2006).

Os carbonetos são formados de acordo com a composição química da liga, processamento prévio e parâmetros de tratamentos térmicos. Apresentam-se sob diferentes tipos, variando sua morfologia, granulometria, composição química, 
distribuição e propriedades mecânicas. Ainda, as propriedades individuais dos carbonetos influenciam as propriedades gerais do aço ferramenta como um todo de segundo Oliveira (2018) e Zeitune (2014). O carboneto de maior presença no aço ferramenta D6 é, provavelmente, $\mathrm{O} \quad \mathrm{M}_{7} \mathrm{C}_{3}$, onde suas dimensões e distribuições influenciam na tenacidade do material e resistência a fadiga, conforme Oliveira (2018).

Os aços ferramentas tipo "D" são obtidos pela fundição de lingotes e posterior laminação, seus carbonetos que suportam altas temperaturas, são deformados no sentido de laminação. Logo suas propriedades mecânicas são anisotrópicas. Resistência e ductilidade ensaiadas por ensaio de tração, compressão e flexão são máximos na direção paralela ao sentido de laminação e mínimas na direção transversal ao sentido de laminação, segundo Roberts, Krauss e Kennedy (1998) pg. 210.

De acordo Roberts, Krauss e Kennedy (1998) com p. 327, carbonetos e inclusões não metálicas em uma matriz de martensita revenida são responsáveis por iniciar e propagar fraturas nos aços ferramentas. Tamanhos, densidades ou distribuição não homogênea destas partículas podem contribuir para a fratura prematura de ferramentas e matrizes. A falta de qualidade em matrizes devido a problemas microestruturais pode gerar falhas prematuras. Nesse caso há transtornos tanto para o cliente final - que deve cessar a produção devido à falha do sistema - como para o fabricante - que deve produzir peças de reposição como garantia, que não geram lucro algum e demandam igualmente de matéria prima e tempo de produção.

Neste contexto, este trabalho tem como objetivo avaliar a microestrutura e a dureza de duas matrizes de aço ferramenta D6: uma matriz que fraturou prematuramente e uma matriz ideal que trabalhou anos sem nunca ter fraturado. Estas matrizes são utilizadas em um equipamento para estampagem de alumínio e foram produzidas pelo mesmo fabricante.

A geometria e o processo de fabricação dos componentes são similares, entretanto os parâmetros de tratamentos térmicos de têmpera e revenimento são desconhecidos, mas controlados em função da dureza requerida.

A partir dos resultados obtidos nessa análise pretende-se definir os motivos para falha prematura do componente e tratar o problema na linha de produção 
evitando futuras falhas que podem acontecer com peças fabricadas em aço ferramenta para trabalho a frio.

\section{REVISÃO DA LITERATURA}

Existem diversos estudos que comparam parâmetros de têmpera e revenimento em aços ferramenta, os quais avaliam principalmente, tenacidade ao impacto, tração e dureza. Apresentam como resultado final a relação entre estas propriedades com as características da sua microestrutura (tamanho de grão da matriz morfologia dos carbonetos, composição química e distribuição).

Mendanha et al. (2003) desenvolveu um trabalho onde analisou a influência da microestrutura de partida de um aço ferramenta, D2, para a trabalho a frio. Nessa microestrutura foi encontrada grande concentração de carbonetos do tipo $M_{7} C_{3}$. As dimensões destes carbonetos foram comparadas no sentido longitudinal à laminação do material e no sentido transversal de tarugos de diâmetros diferentes. Conforme demonstra a Figura 1, foi verificado que os carbonetos se apresentaram mais grosseiros conforme o aumento do diâmetro do tarugo. Em um tarugo com diâmetro de $210 \mathrm{~mm}$, os carbonetos se apresentaram na forma eutética, com tamanho médio mais grosseiro e distribuição menos homogênea. Já o tarugo com diâmetro de 25 $\mathrm{mm}$, apresentou carbonetos bem distribuídos na matriz e com morfologia ideomorfa. Também demostrou que o tamanho dos carbonetos é sempre superior no sentido longitudinal do que no transversal, fato decorrente da anisotropia do material.

Em um determinado trabalho, Junior (2006) analisou a microestrutura de diversos aços ferramentas, para trabalho a frio, alternativos ao D6. Os aços analisados foram o VND (ou O1), VF-800, Vanadis 10 e CALMAX, onde ele relacionou a temperatura de revenimento a diversas propriedades mecânicas. $O$ aço VND apresenta de maneira linear aumento na tenacidade e diminuição na dureza conforme o aumento da temperatura de revenido. 
Figura 1 - Comparativo de microestrutura de um mesmo aço D2 recozido, em diferentes diâmetros e em seções longitudinais e transversais, Nital 10\%. Aumento 90x.

LONGITUDINAL
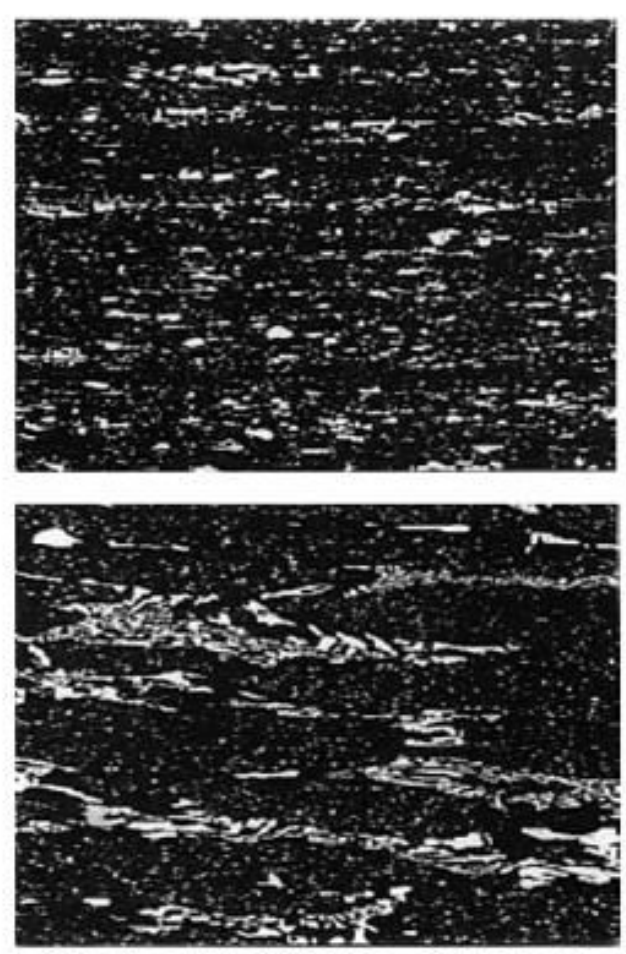

TRANSVERSAL

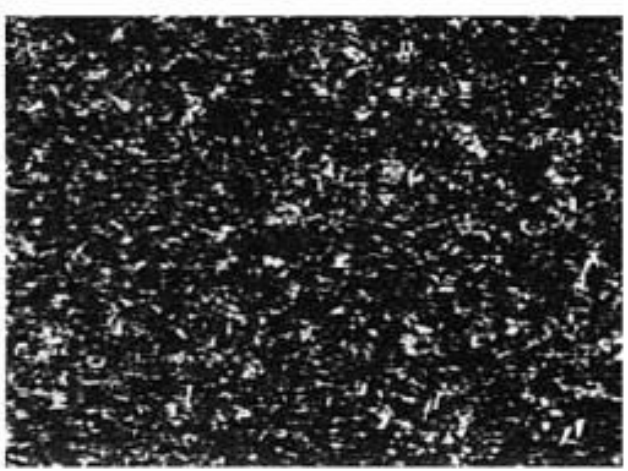

$210,0 \mathrm{~mm}$

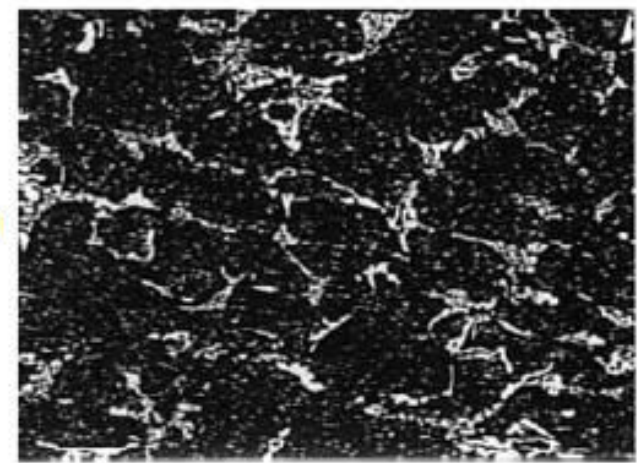

Fonte: Mendanha et al. (2003)

O aço Vanadis 10 apresentou redução de dureza e tenacidade de maneira linear conforme aumento da temperatura de revenimento. Já os outros aços, apresentaram propriedades não lineares em relação ao aumento dessa temperatura, conforme mostra a Figura 2. Com exceção do aço VND, que possui baixo cromo, todos os outros aços apresentam carbonetos primários e secundários em sua estrutura, de maneira bem distribuída e morfologia arredondada.

Em seu trabalho, Zeitune (2014) quantificou e diferenciou a presença de diversos carbonetos distribuídos em um aço ferramenta para trabalho a frio D2 temperado e revenido em diversas temperaturas. Concluiu que quanto maior a temperatura de austenitização, menor a fração volumétrica de carbonetos grandes e pequenos estão presentes na matriz martensítica. 
Figura 02 - Gráfico comparando tenacidade à fratura versus dureza e diversas temperaturas para o aço Calmax.

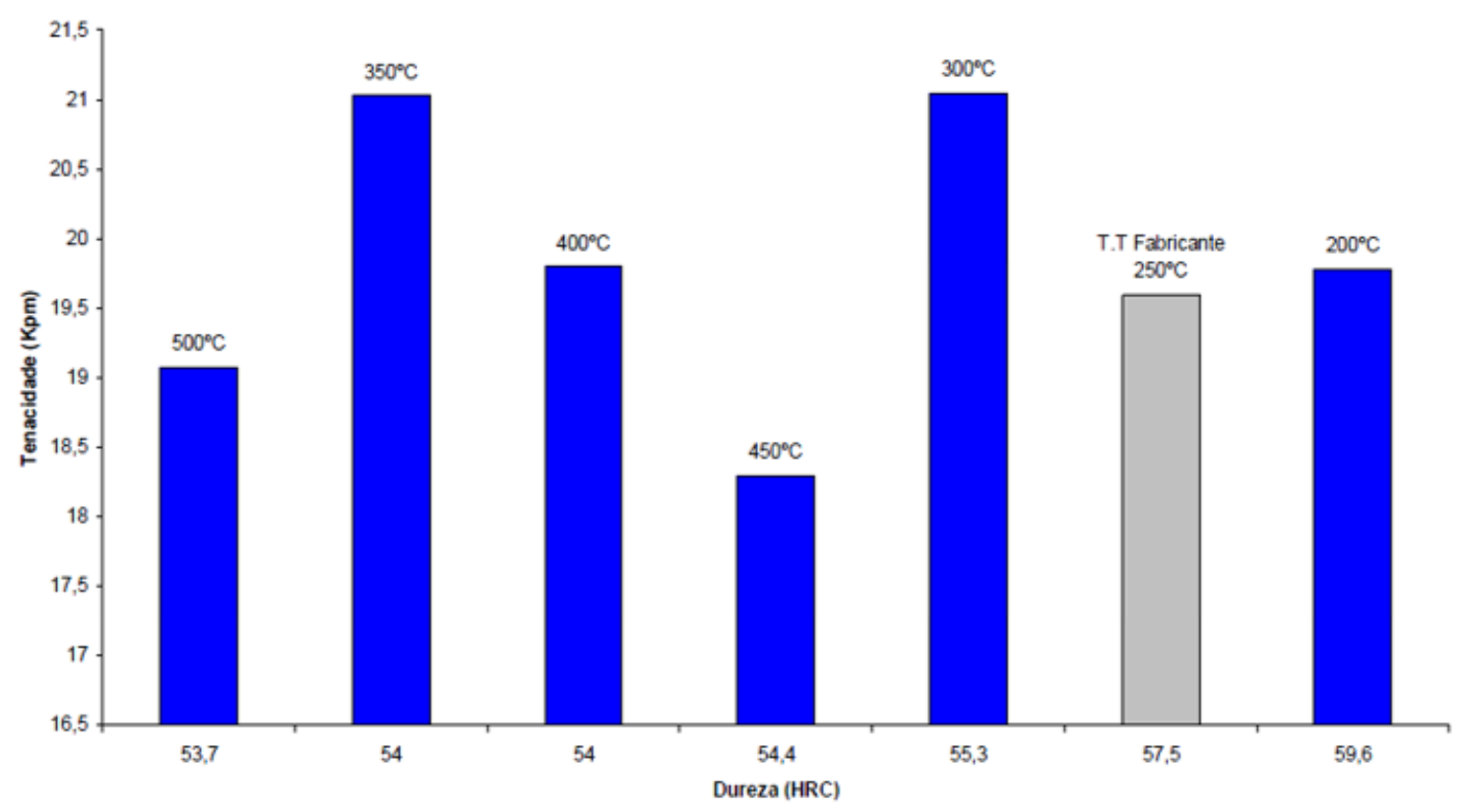

Fonte: Junior (2006)

Já, as temperaturas de revenimento, independentemente da temperatura de austenitização, influenciaram na redução de carbonetos refinados e na dureza, exceto na temperatura de $525{ }^{\circ} \mathrm{C}$, onde ocorreu o oposto, sendo um indício de endurecimento secundário. Entretanto, o mesmo não correlaciona a presença de carbonetos e dureza a outras propriedades mecânicas, como a tenacidade ao impacto.

Oliveira (2018) comparou a presença de carbonetos, o tamanho e sua distribuição em corpos de prova de aço D6 temperado e revenido por uma e duas vezes. As duas amostras apresentam carbonetos com morfologia de ripas, alinhados no sentido de laminação, porém bem distribuídos e homogêneos.

Através da medição das áreas dos carbonetos demonstrou que a matriz que foi revenida apenas uma vez apresenta carbonetos grosseiros, que podem reduzir a tenacidade à fratura. Além disto, a microestrutura que foi revenida duas vezes possui carbonetos primários mais finos e homogeneamente distribuídos, conforme Figura 3. Atestou também que regiões que possuem maior concentração de carbonetos grosseiros, facilitam o caminho de propagação de trincas. O corpo de prova revenido duplamente apresentou uma maior tenacidade a fratura (cerca de 7\% maior). Paralelamente a pesquisa, foi também testado em campo duas lâminas de D6 
tratadas termicamente de acordo com as amostras. A lâmina que foi revenida duas vezes apresentou vida útil média $130 \%$ maior do que a que foi revenida uma única vez (46 dias contra 20 dias).

Figura 3 - As imagens (a) e (b) apresentam a microestrutura do aço revenido uma única vez. As imagens (c) e (d) indicam a microestrutura do aço duplamente revenido.
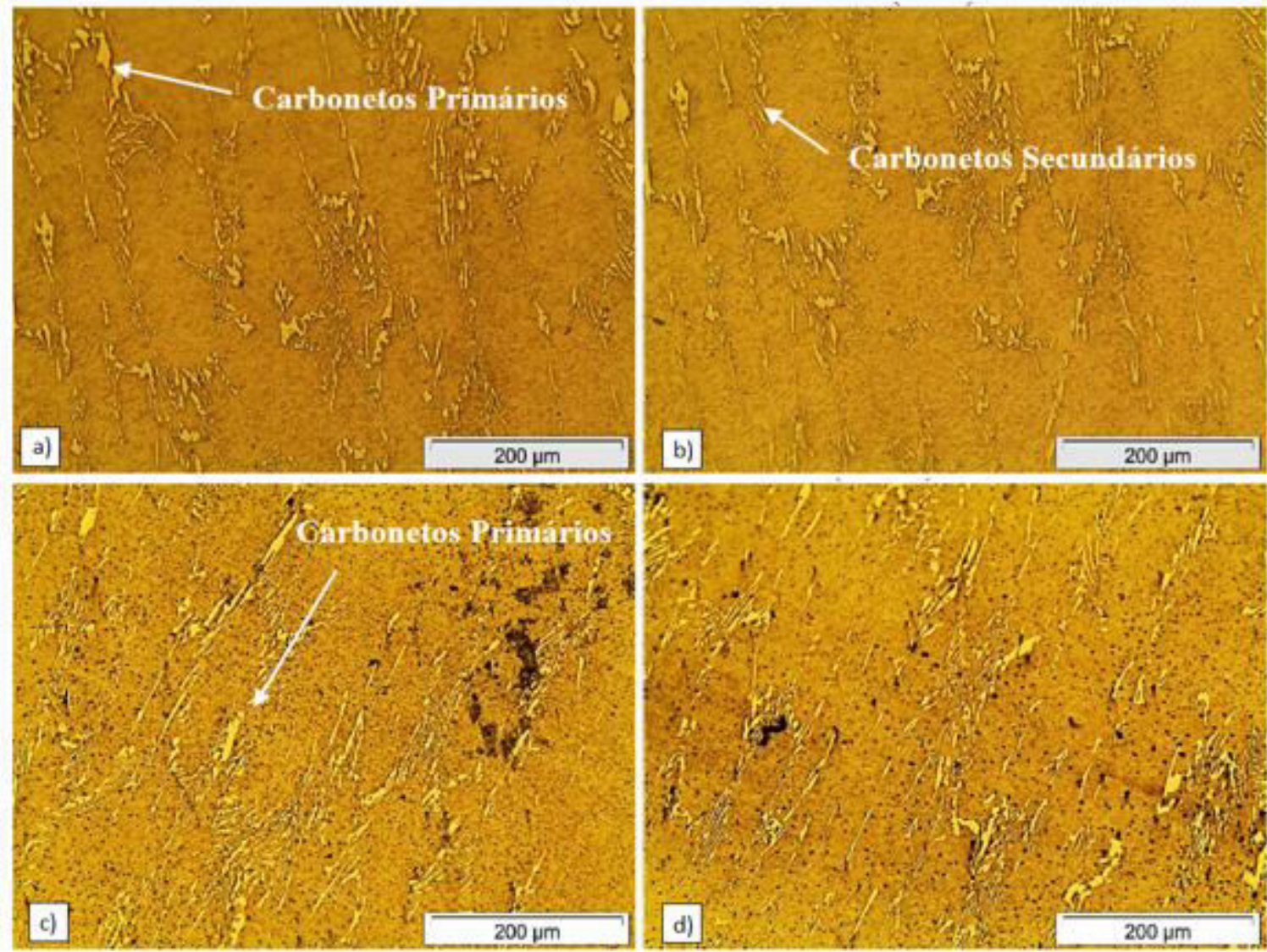

Fonte: Adaptado de Oliveira (2018)

\section{MATERIAIS E MÉTODOS}

\section{ANÁLISE QUIIMICA}

As duas matrizes: a que fraturou prematuramente e a ideal (que trabalhou anos sem fraturar) foram analisadas em um espectrômetro de emissão ótica, para verificar a composição da liga utilizada na produção das matrizes. 


\section{DUREZA}

Foi utilizado um durômetro para realizar a medição de dureza em HRC (Hardness Rockwell C). Cinco endentações foram realizadas em cada matriz e foi utilizada a média aritmética de cada uma.

\section{METALOGRAFIA}

Para verificar a orientação que as matrizes foram fabricadas - em relação ao sentido de laminação do material - cada peça foi seccionada em três corpos de prova, cada um para analisar uma face diferente. Para identificar as amostras, foi utilizado a letra "L" para lateral, "S" para superior e "F" para frontal, de acordo com a orientação da peça em relação à força de atuação, conforme a Figura 4.

Figura 4 - Desenho da matriz com indicações de cada face analisada na microscopia

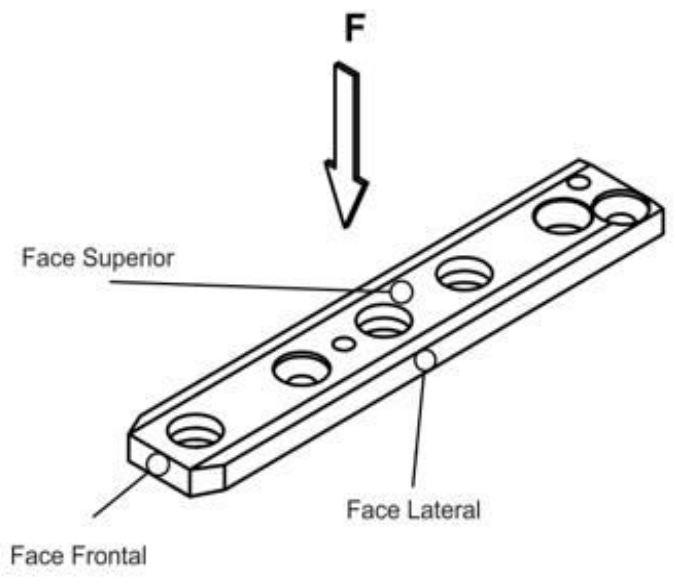

Fonte: O Autor (2019)

Para tanto, as seis amostras foram preparadas utilizando-se o método clássico de preparação metalográfica de acordo com a norma NBR 13284, conforme ABNT (1995), onde as amostras foram embutidas, lixadas, polidas e atacadas utilizando o reagente Nital 10\%, segundo ASM International (2004).

\section{RESULTADOS}

A análise química das matrizes, conforme a Tabela 1, indica que o material é compatível ao aço D6, tendo como característica principal a alta quantidade de 
carbono e cromo. As composições foram tomadas por referências pela norma ABNT NBR NM 122-1:2005, conforme ABNT (2005).

Tabela 1 - Composição química das matrizes analisadas em comparação a norma ABNT NBR NM 122 (Aço para trabalho a frio D6).

\begin{tabular}{|c|c|c|c|c|c|c|c|c|c|c|c|c|}
\hline \multirow[b]{2}{*}{ D6 } & \multicolumn{2}{|c|}{$\begin{array}{c}\text { C } \\
\text { mín. máx. }\end{array}$} & \multicolumn{2}{|c|}{$\begin{array}{c}\text { Mn } \\
\text { mín. máx. }\end{array}$} & \multicolumn{2}{|c|}{\begin{tabular}{|cc}
$P$ & $S$ \\
máx. & máx.
\end{tabular}} & \multicolumn{2}{|c|}{\begin{tabular}{|c}
\multicolumn{2}{c}{$\mathrm{Si}$} \\
mín. máx.
\end{tabular}} & \multicolumn{2}{|c|}{\begin{tabular}{|c}
\multicolumn{2}{c}{$\mathrm{Cr}$} \\
mín. máx.
\end{tabular}} & \multicolumn{2}{|c|}{$\begin{array}{c}\text { W } \\
\text { mín. máx. }\end{array}$} \\
\hline & 2 & 2,2 & 0,2 & 0,4 & 0,03 & 0,03 & 0,1 & 0,4 & 11,5 & 12,5 & 0,6 & 0,9 \\
\hline
\end{tabular}

\begin{tabular}{|c|c|c|c|c|c|c|c|}
\cline { 2 - 7 } \multicolumn{1}{c|}{} & C & Mn & P & S & Si & Cr & W \\
\hline Matriz Ideal & $>1,8$ & 0,272 & 0,05 & 0,01 & 0,229 & $>10,8$ & 0,785 \\
\hline $\begin{array}{c}\text { Matriz } \\
\text { Fraturada }\end{array}$ & $>1,8$ & 0,279 & 0,04 & 0,01 & 0,0279 & $>10,8$ & 0,728 \\
\hline
\end{tabular}

Fonte: O Autor (2019)

A análise de dureza apresentou média aritmética de 59,5 HRC para a matriz ideal e de $58 \mathrm{HRC}$ para a matriz que fraturou.

As metalografias das amostras em relação a todas as faces estão dispostas na Figura 5, com aumento de 100x. As características são compatíveis com o que é encontrado na literatura sobre aço ferramenta temperado e revenido: uma matriz de martensita revenida com a presença de carbonetos (sob diferentes morfologias).

As imagens também indicaram que a orientação dos carbonetos ocorreu de acordo com o sentido de laminação, sendo duas amostras de cada matriz exibindo carbonetos achatados e parcialmente ordenados num sentido e uma amostra exibindo carbonetos ordenados sem orientação, conforme o indicado pela literatura. A matriz ideal apresenta carbonetos alinhados ao sentido de laminação na face superior da peça, já a matriz fraturada apresenta carbonetos alinhados ao sentido de laminação no plano perpendicular da matriz.

A morfologia dos carbonetos na matriz ideal (Figura 5 a, b e c) todos os planos exibem carbonetos com morfologia ideal: carbonetos arredondados e bem distribuídos, garantindo dureza aliada a boa tenacidade do material. 
Figura 5 - Metalografia da matriz ideal de três faces diferentes (a) superior, (b) frontal e (c) lateral. Metalografia matriz fraturada em três faces diferentes (d) superior, (e) frontal e (f) lateral. Setas indicam sentido de laminação.

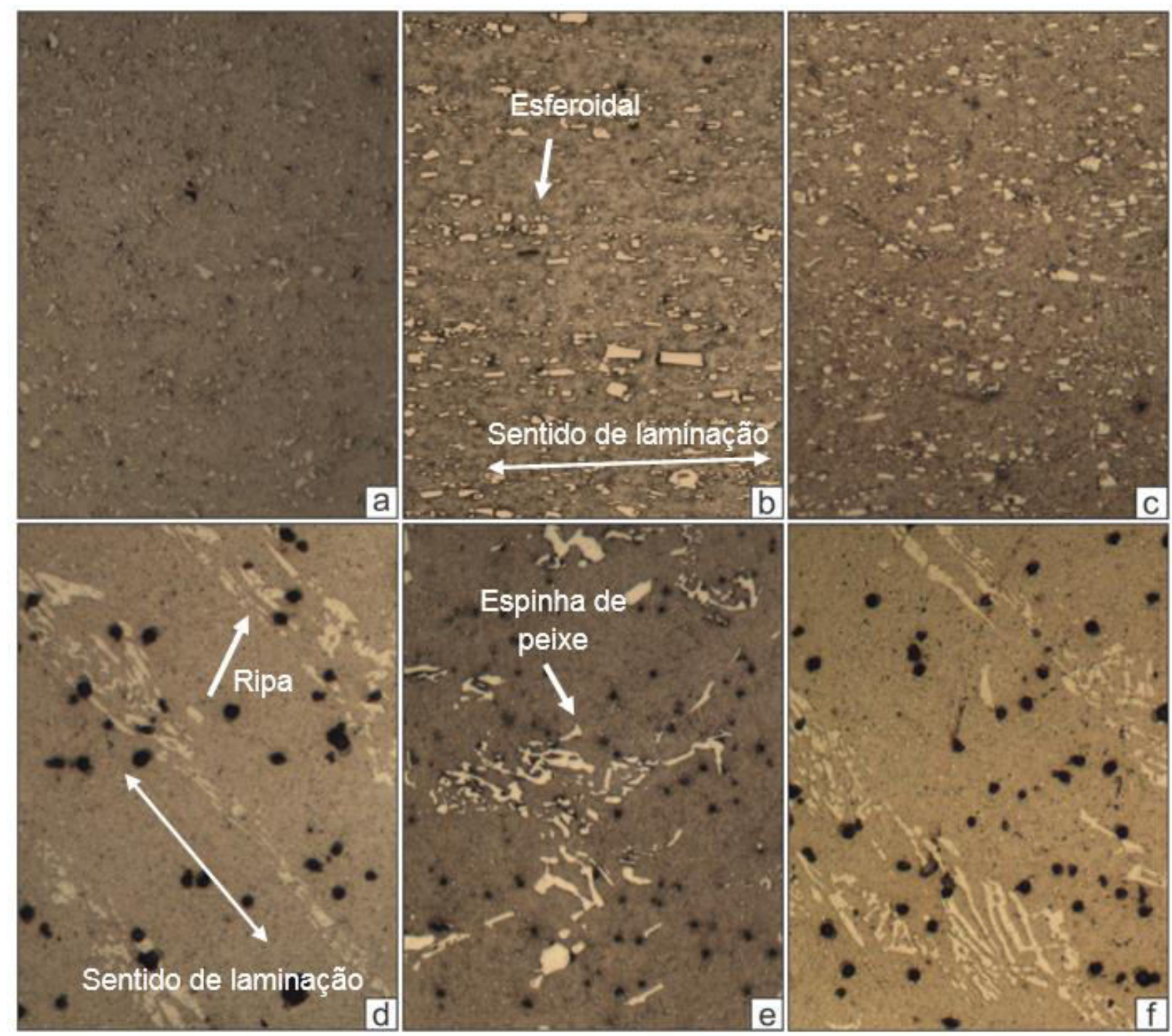

Fonte: O Autor (2019)

As outras imagens (d, e, f), referem-se a matriz fraturada em serviço. Exibem pouquíssimos carbonetos em formato arredondado, porém a maioria em formato tipo espinha de peixe e ligeiramente alongados. As imagens da face superior (d) e da face lateral (f) da matriz apresentam carbonetos alinhados com o sentido de laminação e morfologia de ripas. A imagem frontal da matriz (e) apresenta carbonetos transversais ao sentido de laminação com morfologia de espinhas de peixe. Em geral, as três imagens apresentam má distribuição dos carbonetos, regiões com quantidade maiores de precipitados e ausência dos mesmos em outras regiões, a Figura 6 exibe a face superior da matriz fraturada com ampliação de 400x, dando ênfase em relação a má distribuição de carbonetos e precipitados. 
Figura 6 - Face superior da matriz fraturada com ênfase em má distribuição de carbonetos (400x).

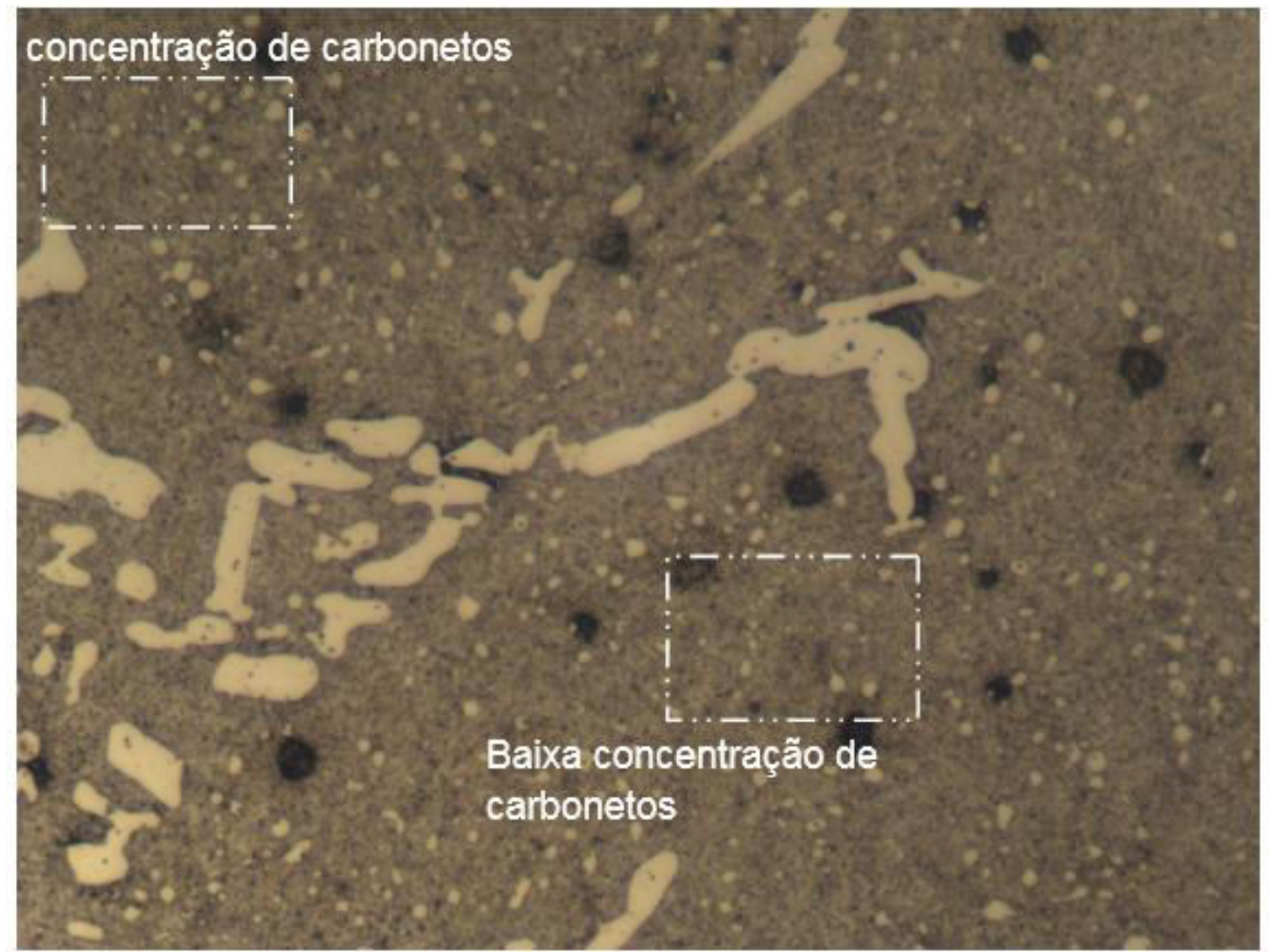

Fonte: O Autor (2019)

\section{DISCUSSÕES}

Ao comparar as metalografias das matrizes com as microestruturas de trabalhos similares e de livros, concluiu-se que a matriz ideal exibe microestrutura com morfologia equivalente as estruturas que apresentam boa tenacidade. Já a matriz fraturada possui microestrutura com morfologia que propicia o início de trincas.

Referente aos carbonetos primários, a principal diferença de morfologia devese ao fato de que provavelmente a matriz ideal foi fabricada de um material laminado em tamanho próximo ao final, justificando o tamanho homogêneo e distribuído de seus carbonetos. Já a matriz fraturada, apresenta morfologia com carbonetos maiores e mais dispersos na matriz, similar ao apresentado pelo trabalho de Mendanha et al (2003).

Outra justificativa à fragilização da matriz, ainda referindo-se aos carbonetos primários, deve-se ao sentido de laminação. Na microestrutura ideal está disposto no plano horizontal da matriz, perpendicular as solicitações de compressão e flexão. Já 
a matriz fraturada, os carbonetos estão alinhados paralelamente às solicitações de compressão e flexão, posição que apresenta menor resistência mecânica, a Figura 7 exemplifica a situação.

Figura 7 - Representação de cada posição da microestrutura em relação a matriz ideal (esquerda) e fraturada (direita). A seta F indica a solicitação aplicada na matriz em sua utilização.

\section{Matriz Ideal}

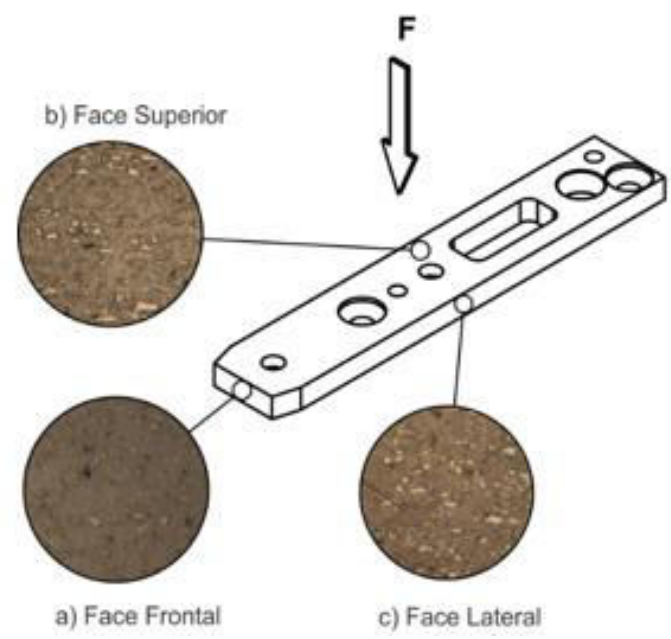

\section{Matriz Fraturada}

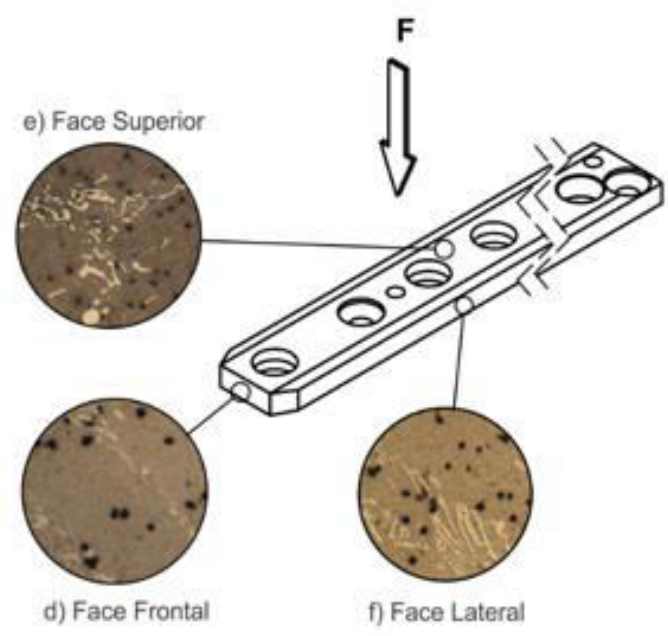

Fonte: O autor (2019)

Outro fator que pode ter reduzido a tenacidade da matriz fraturada é o não uso do revenido duplo, que gera uma diferença de tamanho de carbonetos primários, que podem ser reduzidos na austenitização e revenimento, como ocorrido no trabalho de Zeitune (2014). Já os carbonetos secundários oriundos de revenido, quanto mais finos e mais bem distribuídos, influenciam na tenacidade ao impacto. Essa característica foi apenas observada na matriz ideal.

Ainda, como visto no trabalho de Junior (2006), não há relação linear entre a temperatura de revenimento e as propriedades mecânicas, atestando que a escolha da temperatura não deve ser relacionada apenas com a dureza desejada, mas também de acordo com um melhor aproveitamento da relação de tenacidade, dureza e outras propriedades. Essa não linearidade das propriedades no revenido pode ser explicada por Callister e Rethwish (2012) pg. 322, que a resistência ao impacto do aço pode ser diminuída se o mesmo for revenido em temperaturas entre $375^{\circ} \mathrm{C}$ e $575^{\circ} \mathrm{C}$ principalmente nos aços que contem concentrações apreciáveis de cromo, níquel e manganês.

A austenita retida não foi caracterizada neste estudo, entretanto também pode ser uma influência positiva ou negativa na tenacidade do material. Como sugestão 
de trabalhos futuros, fica a determinação da fração de austenita retida em amostras de matrizes similares, fraturadas e não fraturadas, entretanto preferencialmente conhecendo as temperaturas de tempera, revenimento e origem da matéria prima.

\section{CONSIDERAÇÕES FINAIS}

Referente à microestrutura das matrizes, a apresentada pela matriz ideal contém carbonetos arredondados e bem distribuídos, em todas as faces. Ainda, a matriz ideal foi fabricada no sentido de laminação do material, aproveitando melhores propriedades de resistência mecânicas devido a anisotropia do material laminado. Estes fatores podem justificar a boa tenacidade e longevidade de trabalho da ferramenta.

Já a microestrutura da matriz que falhou em serviço apresentou carbonetos amorfos (tipo espinha de peixe) e mal distribuídos, visto que foi utilizado matéria prima laminada, e provavelmente de dimensões muito superior à da utilização final. Além disso, foi fabricada no sentido transversal ao sentido de laminação, local onde este material anisotrópico apresenta menor resistência mecânica.

A dureza mostrou-se como um fator que não deve ser tomado exclusivamente como requisito de qualidade do material, justificando que nem sempre uma matriz que apresenta a dureza esperada, irá se comportar igual. Logo outros fatores, como resistência mecânica e tenacidade devem ser levados em consideração na análise de qualidade da ferramenta.

A partir dos resultados obtidos nessa análise pretende-se tratar o problema na linha de produção para evitar futuras falhas, por meio de um estudo aprofundado sobre tratamentos térmicos para controlar a morfologia dos carbonetos, os quais são os principais responsáveis nas propriedades desses materiais.

\section{REFERÊNCIAS}

ABNT, Associação Brasileira de Normas Técnicas - Preparação de corpos-deprova para análise metalográfica - Procedimento, Rio de Janeiro, ABNT, 1995. Rio de Janeiro, ABNT, 2005. 
ASM INTERNATIONAL. ASM Handbook, Metallography and Microstructures Volume 9. [s.I.] ASM International, 2004. v. 9

CALLISTER, W. D.; RETHWISCH, D. G. Ciência e Engenharia de Materiais. Uma Introdução. 8. ed. Rio de Janeiro: LTC, 2012.

JUNIOR, E. S. "Efeito do tratamento térmico na microestrutura e nas propriedades mecânicas de aços-ferramenta para trabalho a frio". São Paulo: Universidade de São Paulo, 18 set. 2006.

MENDANHA, A.; GOLDENSTEIN, H.; PINEDO, C. E. Tenacidade do Aço Ferramenta Para Trabalho a Frio Aisi D2 - Parte I Influência da Microestrutura de Partida. $1^{\circ}$ Encontro de Integrantes da Cadeia Produtiva de Ferramentas, Moldes e Matrizes", 29 - 30 de outubro de 2003. São Paulo/SP, v. 2, n. 1, p. 189196, 2003.

OLIVEIRA, W. C. Estudo da viabilidade de uso do aço ferramenta AISI D6 para corte de placas de baterias chumbo-ácido. Campina Grande: Universidade Federal de Campina Grande, 2018.

ROBERTS, G.; KRAUSS, G.; KENNEDY, R. Tool steels. 5. ed. ASM INTERNATIONAL, 1998

SILVA, A. L. V. DA C. E; MEI, P. R. Aços e ligas especiais. 3. ed. São Paulo: Blücher, 2010.

ZEITUNE, L. H. Efeito dos Parâmetros de Têmpera e Revenimento na Microestrutura e na Dureza de um Aço Ferramenta para Trabalho a Frio. Belo Horizonte: CEFET-MG, 2014. 